
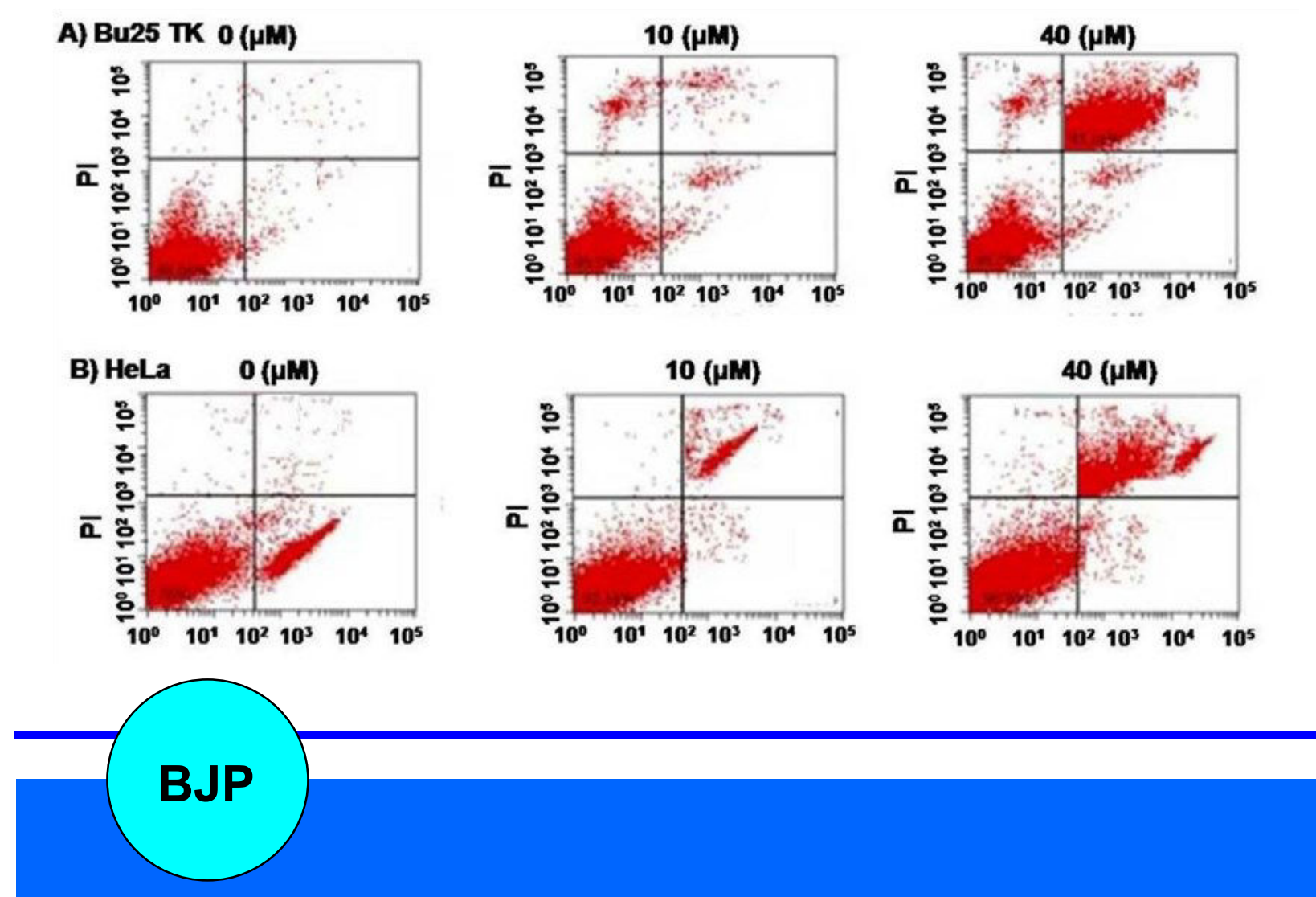

Bangladesh Journal of Pharmacology

Research Article

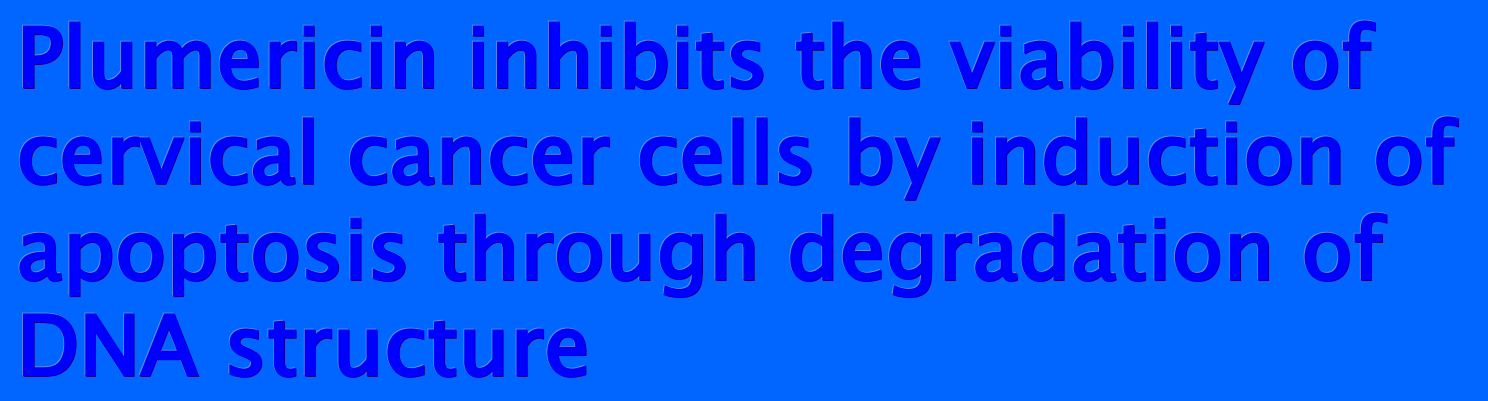


Abstracted/indexed in Academic Search Complete, Asia Journals Online, Bangladesh Journals Online, Biological Abstracts, BIOSIS Previews, CAB Abstracts, Current Abstracts, Directory of Open Access Journals, EMBASE/Excerpta Medica, Google Scholar, HINARI (WHO), International Pharmaceutical Abstracts, Open J-gate, Science Citation Index Expanded, SCOPUS and Social Sciences Citation Index;

ISSN: $1991-0088$

\title{
Plumericin inhibits the viability of cervical cancer cells by induction of apoptosis through degradation of DNA structure
}

\author{
Jing Sun', Jing Wu1, Li Zhang², Qi-Yue Wan³, Li-Ci Wang1, Yao-Yang Liu', \\ Rong-Mei Wang1 and De-Qing Sun'1
}

${ }^{1}$ Department of Pharmacy, The Second Hospital of Shandong University, 250 033, China; ${ }^{2}$ Department of Pharmacy, The People's Hospital of Guangxi Huang Autonomous Region, Nanning, 530 021, China; ${ }^{3}$ Department of Pharmacy, Qi Lu Hospital of Shandong University, Jinan 250 012, China.

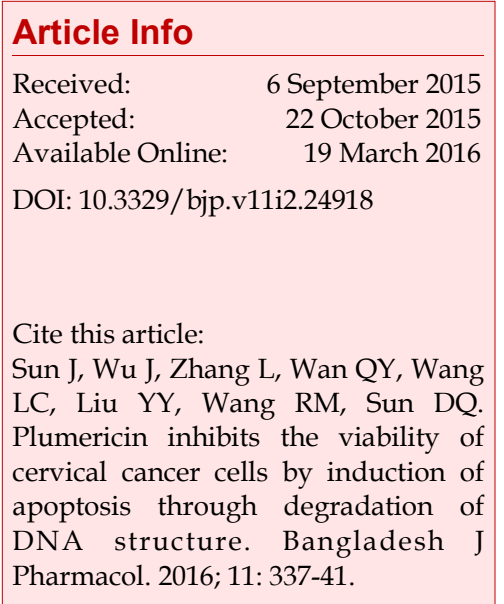

\begin{abstract}
The current study demonstrates the effect of plumericin on the viability and induction of apoptosis through degradation of double helical DNA structure in Bu25TK and HeLa cervical carcinoma cell lines. Plumericin treatment exhibited concentration- and time-dependent effect on the viability of Bu25TK and HeLa cells. Incubation of Bu25TK and HeLa cells with $40 \mu \mathrm{M}$ concentration of plumericin decreased cell viability to 24 and $29 \%$, respectively after 48 hours. Plumericin treatment also caused significant increase in the proportion of apoptotic cells in both the cell lines at $40 \mu \mathrm{M}$ concentration compared to the control cells. Examination of the DNA double helical structure after 48 hours of treatment with plumericin at $40 \mu \mathrm{M}$ concentration showed DNA degradation and formation of comets. Thus, plumericin exhibits inhibitory effect on the viability of Bu25TK and HeLa cells and induced apoptosis through DNA degradation. Therefore, plumericin is a potent candidate for the treatment of cervical carcinoma.
\end{abstract}

\section{Introduction}

Cervical cancer rate has shown increasing trend in the women of young age and comprises the second frequently detected cancer in females throughout the globe (Phongsavan et al., 2010; Wang et al., 2010). It is estimated that every year around 275,000 deaths occur due to cervical cancer and half million cases are detected (Agarwal et al., 2011). Although in most of the cervical cancer cases human papilloma-virus (HPV) has been found to be associated but the cause appears not HPV alone (Kawase et al., 2010).

The mechanisms underlying the cervical cancer is yet to be fully understood (Dursun et al., 2008). The early stages of the cervical cancer are asymptomatic which results in its detection at the advanced stage (Dursun et al., 2008). At present women are advised Pap tests at regular intervals which has increased the rate of cervical cancer detection at early stage making the treatment favorable (Parkin et al., 2005; Morice and Castaigne, 2005).

The currently used strategy for the treatment involves radical surgery in combination with adjuvant chemotherapy. Despite advancement in the field of diagnostic techniques and radical surgery the rate of prognosis in the cervical carcinoma patients is very poor. Therefore, cervical cancer is considered to be the serious concern at present both in developing as well as developed countries. Thus, the discovery of novel molecules and targets for the treatment of cervical cancer is very important (Long, 2007; Brinkman et al., 2005).

Plumericin (Figure 1) has been isolated during the phytochemical investigation of the plant Plumeria bicolor in the polar medium (Little and Johnstone, 1951). The furofuranone containing natural product has been reported to exhibit wide range of biological activities including, antifungal, antibacterial, antitumor potential. 


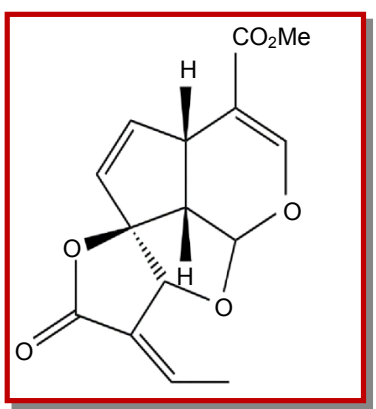

Figure 1. Chemical structure of plumericin

The present study was aimed to investigate the effect of plumericin on the cell viability, DNA damage and apoptosis in the cervical cancer cells.

\section{Materials and Methods}

\section{Cell lines}

Bu25TK and HeLa cervical cell lines were purchased from American Type Culture Collection (USA). Both the cell lines were cultured in Dulbecco's modified Eagle's medium (DMEM) containing 10\% fetal bovine serum (FBS) and antibiotics. Incubation of the cells was performed in an incubator at $37^{\circ} \mathrm{C}$ in humidified atmosphere of $5 \% \mathrm{CO}_{2}$ and $95 \%$ air.

\section{Chemicals and reagents}

Plumericin was isolated during phytochemical analysis of the plant Plumeria bicolor. 4',6-diamidino-2-phenylindole (DAPI), dimethyl sulfoxide (DMSO) and $\mathrm{N}$ methyl-N-nitro-N-nitrosoguanidine were purchased from Sigma-Aldrich. DMEM and propidium iodide were ordered from BD Pharmingen (USA).

\section{Cell viability assay}

Viability of Bu25TK and HeLa cervical carcinoma cells was determined by CCK-8 (Dojindo Molecular Technologies Inc.) assay. The cells were treated with different concentrations of plumericin from 10-50 $\mu \mathrm{M}$ for 12, 24, 36 and 48 hours. Briefly, the cells were distributed at a density of $2 \times 10^{6}$ cells per well onto the 96-well culture plates and allowed to adhere overnight. Then different concentrations of plumericin were added to each well of the 96-well plates and incubated for various time periods. After incubation, CCK-8 solution $(10 \mu \mathrm{L})$ was put into each well. Incubation of the plates was continued for 2 hours more at $37^{\circ} \mathrm{C}$ followed by measurement of reading at $465 \mathrm{~nm}$ by using microplate reader (Bio-Rad, USA).

\section{Analysis of apoptosis in Bu25TK and HeLa cells by flow cytometry}

The cells were stained with an annexin V-FITC apoptosis detection kit (MBL) to determine whether cells are undergoing apoptosis. Propidium iodide staining was used as a control to differentiate cells undergoing necrosis. The cells distributed at a density of $1 \times 10^{5}$ onto the tissue culture slides were permitted to attach for 24 hours. The cells were then treated for 48 hours with various concentrations of plumericin and resuspended in $300 \mu \mathrm{L}$ of $1 x$ binding buffer. To each of the slide, annexin V-FITC (5 $\mu \mathrm{L})$ and propidium iodide $(5 \mu \mathrm{L})$ was added followed by incubation at $37^{\circ} \mathrm{C}$ for 5 min under dark conditions. Into each of slide, apoptotic cells were count using fluorescent microscopy. The effect of plumericin on the viability apoptosis in the cervical carcinoma cells. The cells after treatment with $40 \mu \mathrm{M}$ concentration of plumericin for 48 hours were rinsed twice in PBS, fixed in $70 \%$ ethyl alcohol and subjected to propidium iodide staining. After staining, the cells were analyzed by flow cytometry (BD Facs Calibur).

\section{DNA extraction and the detection of DNA fragmenta- tion}

Both the cervical carcinoma cell lines were incubated with 10-40 $\mu \mathrm{M}$ concentration of plumericin for 12, 24, 36 and 48 hours. Following incubation the cells were harvested, rinsed twice in phosphate-buffered saline (PBS) and subjected to DNA extraction. The DNA extraction was performed by Wizard Genomic DNA Purification kit (Promega Corporation, USA). For the purpose of analysis of fragmentation of DNA electrophoresis was carried out on denatured urea polyacrylamide gel after staining in silver nitrate.

\section{Comet assay}

The cells were seeded at a density of $2 \times 10^{6}$ cells onto each slide and embedded in $1 \%$ low-melting agarose. The cell lysis was then performed using lysis buffer (1.25 M NaCl, $50 \mathrm{mM}$ Na-EDTA, $0.1 \%$ sodium $\mathrm{N}$ lauroylsarcosine, $100 \mathrm{mM}$ Tris- $\mathrm{HCl}, \mathrm{pH} 10)$. The cells were digested using proteinase $\mathrm{K}(1.25 \mathrm{M} \mathrm{NaCl}, 5 \mathrm{mM}$ Tris- $\mathrm{HCl}, 5 \mathrm{mM}$ EDTA, $0.5 \mathrm{mg} / \mathrm{mL}$ proteinase $\mathrm{K}$, $\mathrm{pH}$ 10) followed by precipitation of DNA (50\% ethanol, 1 $\mathrm{mg} / \mathrm{mL}$ spermine, $20 \mathrm{mM}$ Tris- $\mathrm{HCl}, \mathrm{pH}$ 7.4). Analysis of the breaks in single-stranded DNA was performed by soaking of slides in alkaline buffer $(0.18 \mathrm{M} \mathrm{NaOH}$, $0.6 \mathrm{mM}$ NaEDTA, pH 13) followed by electrophoresis. Breaks in the double-stranded DNA were analyzed by unwinding it in neutralizing buffer (0.2\% DMSO, 500 $\mathrm{mM}$ Na-EDTA, $100 \mathrm{mM}$ Tris- $\mathrm{HCl}, 500 \mathrm{mM} \mathrm{NaCl}, \mathrm{pH}$ 9.0) followed by electrophoresis. The cells were subjected to thidium bromide staining to assess the formation of comets. The cells were observed under light microscope connected to a digital camera having filters for 510 excitation and 590 emission. Comet Assay IV (Perspective Instruments, UK) was used for the analysis of the images.

\section{Statistical analysis}

The experiments were performed in triplicates each and 
results are presented as mean \pm SEM. For the purpose of statistical analysis Sigma Plot 2001 software was used. $\mathrm{p}<0.05$ was considered to indicate a statistically significant difference.

\section{Results}

\section{Inhibitory effect on the cell growth}

The results from CCK-8 assay demonstrated that cell viability decreased to 24 and $29 \%$ in Bu25TK and HeLa cells, respectively compared to $100 \%$ in the control with the increase in concentration of plumericin from 10 to $40 \mu \mathrm{M}$ (Figure 2). Treatment of Bu25TK and HeLa cells with $40 \mu \mathrm{M}$ concentration of plumericin for 12, 24 and 48 hours reduced the viability of Bu25TK cells to 86, 52 and $24 \%$, respectively. Similarly, in HeLa cells viability was decreased to 89,61 and $29 \%$, respectively after 12 , 24 and 48 hours (Figure 2).

\section{Induces apoptosis in Bu25TK and HeLa cells}

The results from flow cytometry and DNA fragmentation showed induction of apoptosis significantly in both Bu25TK and HeLa cell lines on treatment with $40 \mu \mathrm{M}$ concentration of plumericin for 48 hours. In the cervical carcinoma cells treatment with plumericin caused formation of ladder like pattern in DNA, however, no such changes were present in the DNA of untreated cells. Fragmentation of DNA was evident in the cervical carcinoma cells after incubation with plumericin for 48 hours (Figure 3). The proportion of apoptotic cells in Bu25TK and HeLa cell cultures increased with the increase in concentration of plumericin from 10 to 40 $\mu \mathrm{M}$ (Figure 3A-D). The proportion of apoptotic cells in Bu25TK and HeLa cell cultures was found to be 73 and $69 \%$, respectively following treatment with $40 \mu \mathrm{M}$ concentration of plumericin for 48 hours.

\section{Plumericin treatment induces DNA damage in Bu25TK and HeLa cells}

The results from comet assay showed that plumericin treatment induced degradation of double helical DNA structure and formed comet-shaped structures. Compared to the control Bu25TK and HeLa cells, plumericin treatment caused a marked increase in the proportion of comet-positive cells (Figure 4).

\section{Discussion}

The present study demonstrated that plumericin treatment reduced the viability of cervical cells through induction of apoptosis by DNA damage.

Inhibition of carcinoma cell growth by treatment with natural products is considered to be the promising strategy for treatment of various cancers. The current study demonstrated that cell viability decreased significantly $(p=0.005)$ in Bu25TK and HeLa cells compared to the control with the increase in concentration of plumericin to $40 \mu \mathrm{M}$. The viability of carcinoma cells can be inhibited by induction of various cellular processes including, apoptosis, necrosis, autophagy, etc. (Bras et al., 2005; Broker et al., 2005; Edinger and Thompson, 2004). Cell apoptosis is initiated by activation of the apoptotic factors which lead to the condensation of chromatin material and degradation of the DNA double helical structure (Robertson and Orrenius, 2002). Several anti-cancer drugs exhibit their effect through apoptosis induction and DNA structure degradation. In the current study, plumericin treatment caused significant damage to the DNA in concentration dependent manner. Plumericin treatment enhanced the population

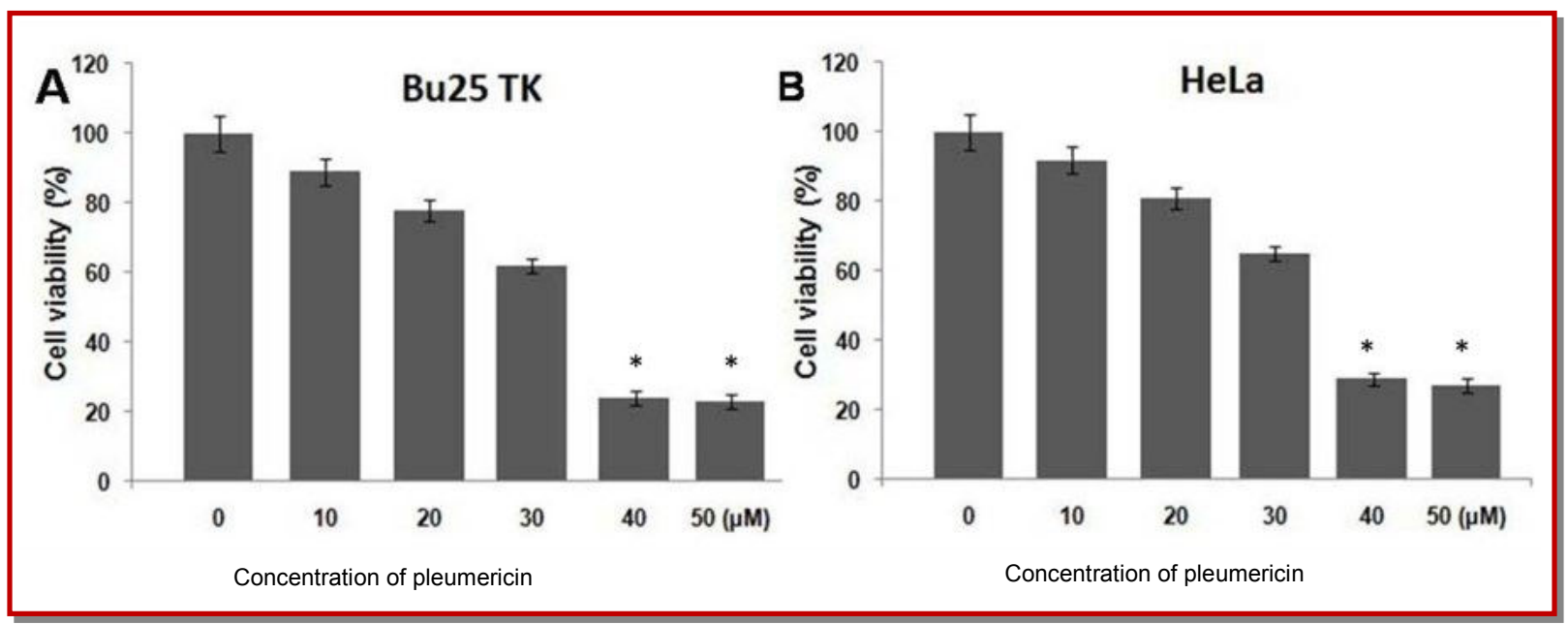

Figure 2: Inhibition of cell viability in cervical carcinoma cells by plumericin. The cervical carcinoma cell lines, Bu25TK and HeLa were incubated with various concentrations of plumericin for 12, 24, 36 and 48 hours followed by analysis using MTT assay. The data presented are the mean \pm S. D. of three independently performed experiments. ${ }^{*} p<0.05$, in comparison to the control cells. MTT, 3-(4,5-dimethyl- thiazol-2-yl)-2,5-diphenyltetrazolium bromide 


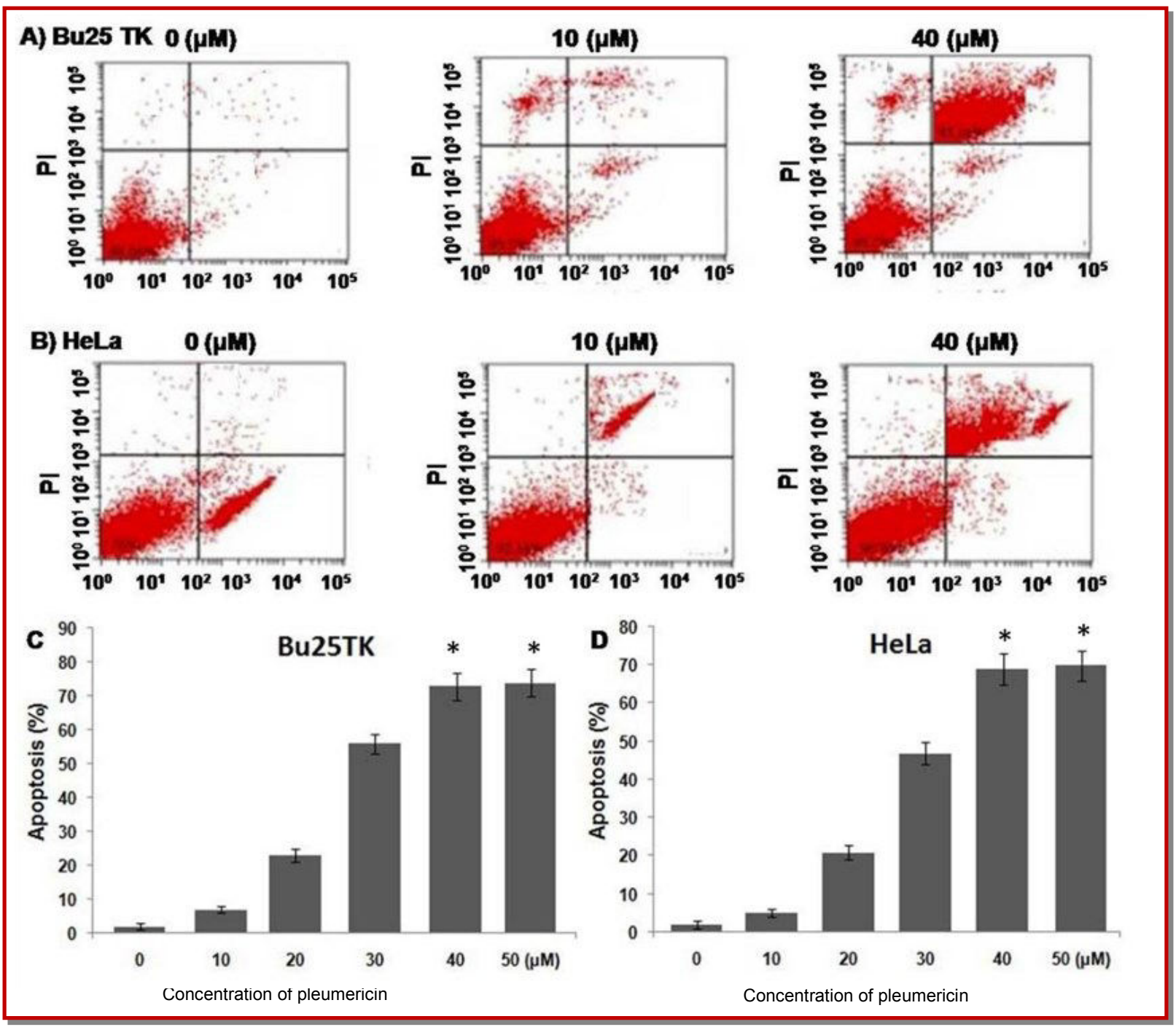

Figure 3: Induction of apoptosis in Bu25TK and HeLa carcinoma cells by plumericin. (A) Analysis of apoptosis in Bu25TK and HeLa by annexin-V and PI staining. (B, C) Proportion of apoptotic cells following 48 hours of incubation with plumericin. The data presented are the mean \pm S.E. of the three experiments performed independently. ${ }^{*} \mathrm{p}<0.05$, compared with the control

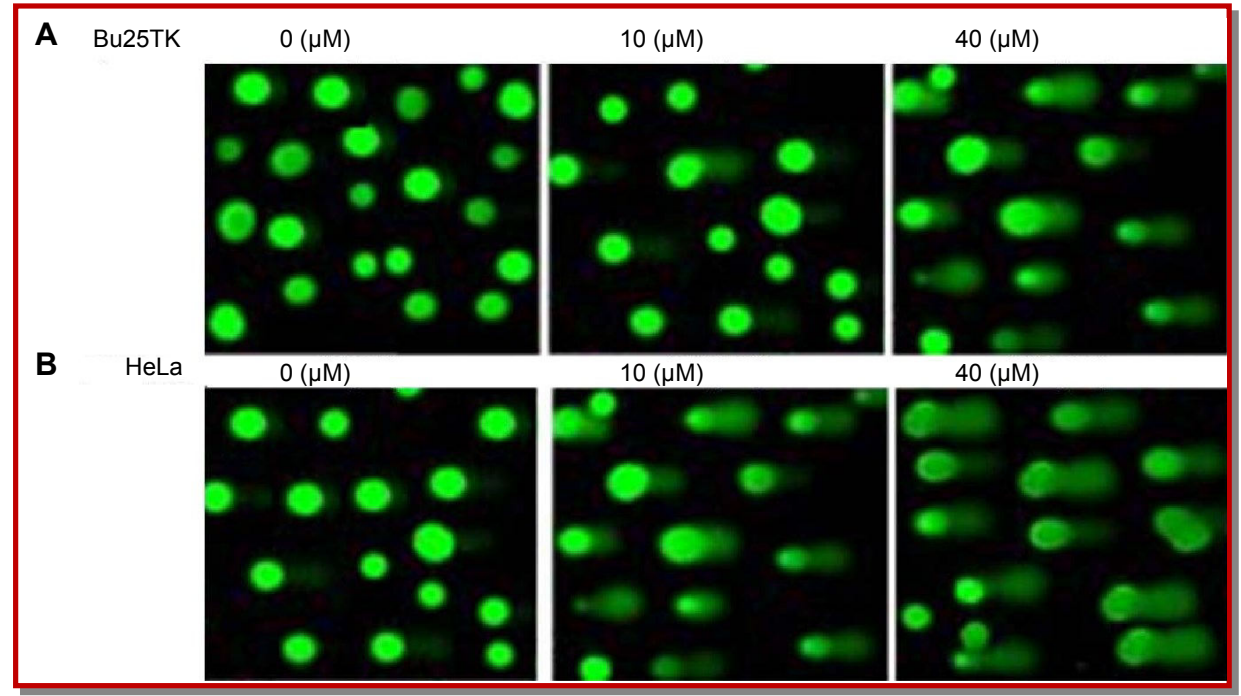

Figure 4: Analysis of DNA degradation in Bu25TK and HeLa cells by comet assay. The images of the cells were captured at a magnification of $\times 200$. The cells were treated with $40 \mu \mathrm{M}$ concentration of plumericin for 48 and N-methyl-N-nitro-N-nitrosoguanidin was taken as the control 
of apoptotic cells significantly compared to the control cervical cells. Analysis of DNA degradation by comet assay (Cotelle and Férard, 1999) showed increase in the percentage of comet positive cervical cells on treatment with plumericin compared to the control cells.

\section{Conclusion}

Plumericin treatment exhibits inhibitory effect on the viability of cervical carcinoma cells by causing damage to the cell DNA and inducing apoptosis. Thus, plumericin can be used as a promising candidate for the treatment cervical carcinoma.

\section{References}

Agarwal SM, Raghav D, Singh H, Raghava GP. CCDB: A curated database of genes involved in cervix cancer. Nucleic Acids Res. 2011; 39: D975-79.

Bras M, Queenan B, Susin SA. Programmed cell death via mitochondria: Different modes of dying. Biochemistry (Mosc). 2005; 70: 231-39.

Brinkman JA, Caffrey AS, Muderspach LI, Roman LD, Kast WM. Inhibitory effect of ginsenoside Rg5 and its metabolite ginsenoside $\mathrm{Rh} 3$ in an oxazolone induced mouse chronic dermatitis model. Eur J Gynaecol Oncol. 2005; 26: 129-42,

Broker LE, Kruyt FA, Giaccone G. Cell death independent of caspases: A review. Clin Cancer Res. 2005; 11: 3155-62.
Cotelle S, Férard JF. Comet assay in genetic ecotoxicology: A review. Environ Mol Mutagen. 1999; 34: 246-55.

Dursun P, Ayhan A, Kuscu E. New surgical approaches for the management of cervical carcinoma. Eur J Surg Oncol. 2008; 34: 487-96.

Edinger AL, Thompson CB. Death by design: Apoptosis, necrosis and autophagy. Curr Opin Cell Biol. 2004; 16: 66369.

Kawase R, Ishiwata $\mathrm{T}$, Matsuda $\mathrm{Y}$, et al. Expression of fibroblast growth factor receptor 2 IIIc in human uterine cervical intraepithelial neoplasia and cervical cancer. Int J Oncol. 2010; 36: 331-40.

Long $\mathrm{HJ} 3^{\text {rd }}$. Management of metastatic cervical cancer: Review of the literature. J Clin Oncol. 2007; 25: 2966-74.

Little JE, Johnstone DB. Plumericin: An antimicrobial agent from Plumeria multiflora. Arch Biochem. 1951; 30: 445-52.

Morice P, Castaigne D. Advances in the surgical management of invasive cervical cancer. Curr Opin Obstet Gynecol. 2005; 17: 5-12.

Parkin DM, Bray F, Ferlay J, Pisani P. Global cancer statistics, 2002. CA Cancer J Clin. 2005; 55: 74-108.

Phongsavan K, Phengsavanh A, Wahlstrom R, Marions L. Women's perception of cervical cancer and its prevention in rural Laos. Int J Gynecol Cancer. 2010; 20: 821-26.

Robertson JD, Orrenius S. Role of mitochondria in toxic cell death. Toxicology 2002; 182: 491-96.

Wang X, Liu R, Ma B, et al. High dose rate versus low dose rate intracavity brachytherapy for locally advanced uterine cervix cancer. Cochrane Database Syst Rev. 2010; CD007563. 


\section{Your feedback about this paper}

1. Number of times you have read this paper 0

2. Quality of paper Click

3. Your comments

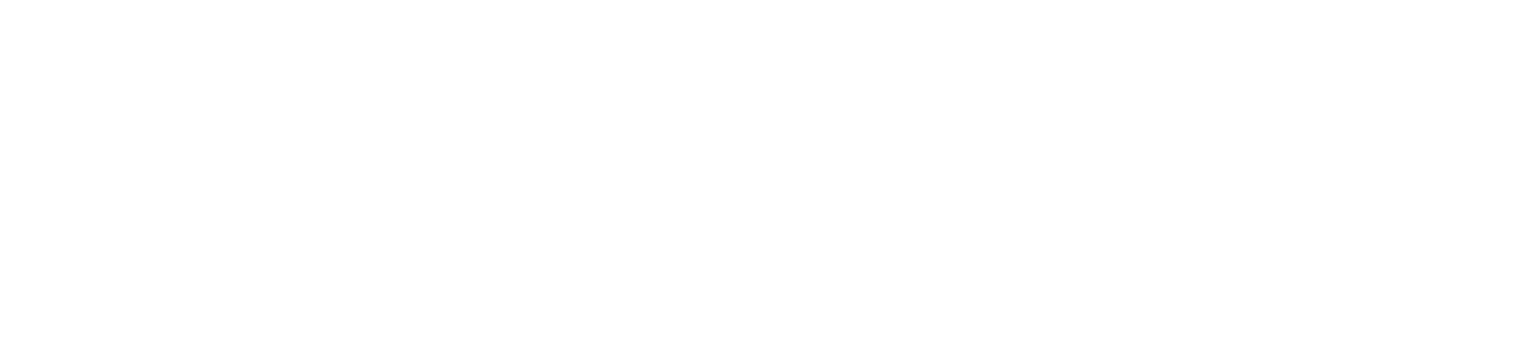

